\title{
Design, synthesis and selective functionalization of a rigid, truxene derived pure blue-emitting chromophore
}

\author{
Banpreet Kaur, ${ }^{[a]}$ Safakath Karuthedath, ${ }^{[b]}$ Catherine S. P. De Castro, ${ }^{[b]}$ Frédéric Laquai, ${ }^{[b]}$ and \\ Josemon Jacob*[a]
}

\begin{abstract}
A novel, rigid, solution processable, blue emitting chromophore based on an extended core of truxene (ExT) was designed and synthesized. The core, ExT based on a fused cyclic trimer of indenofluorene, was found to be planar in nature and a potential precursor for blue emission. This could be selectively brominated under mild conditions to generate a tribromo derivative which underwent ready Suzuki coupling to generate a trisubstituted pyrene derivative, ExT-P. This coupling alters the kinetics of the excited state considerably as evident from transient absorption spectroscopy, showing faster singlet state decay and less triplet state formation in the case of the pyrene coupled ExT-P ( 1.6 ns) compared to ExT ( 17 ns). The ExT-P shows emission maxima at $441 \mathrm{~nm}$ and $442 \mathrm{~nm}$ in tetrahydrofuran solution and film, respectively, with high fluorescence quantum yield (0.97). The negligible bathochromic shift in the solid-state emission and narrow full width at half maximum suggests practically no aggregation and pure blue emission in the target molecule due to bulky and rigid core.
\end{abstract}

\section{Introduction}

Polycyclic aromatic hydrocarbons are one of the most extensively researched materials in the field of organic electronics. These conjugated materials have found applications in organic photovoltaics (OPV), ${ }^{[1]}$ organic light emitting diodes (OLED), ${ }^{\left[{ }^{[2]}\right.}$ organic field effect transistors (OFET), ${ }^{[3]}$ light emitting electrochemical cells (LEC), ${ }^{[4]}$ dye-sensitized solar cells (DSSC) ${ }^{[5]}$ etc, primarily due to their ease of chemical tailoring, which ultimately helps in achieving the desired properties by structural modification. ${ }^{[6]}$ These materials also exhibit high thermal and oxidative stability, high quantum efficiency, along with good charge carrier mobilities. ${ }^{[2 a, 7]}$ Pope et al. were the first to demonstrate electroluminescence (EL) from anthracene crystals albeit at a high voltage of $400 \mathrm{~V}{ }^{[8]}$ Since then, various conducting organic materials, both small molecules and polymers, have been explored for various organic electronic applications. Polycyclic aromatic hydrocarbons continue to attract interest from industry and academia alike due to their interesting optoelectronic

[a] B. Kaur, J. Jacob

Department of Materials Science and Engineering, Indian Institute of Technology Delhi, Hauz Khas, New Delhi 110016, India

E-mail: jacob@mse.iitd.ac.in (J. Jacob)

[b] S. Karuthedath, C. S. P. De Castro, F. Laquai King Abdullah University of Science and Technology (KAUST), KAUST Solar Center (KSC), Physical Sciences and Engineering Division (PSE), Material Science and Engineering Program (MSE), Thuwal 23955-6900, Kingdom of Saudi Arabia

Supporting information for this article is given via a link at the end of the document. properties obtained by virtue of their delocalized $\pi$-electrons and planar rigid structures. ${ }^{[9]}$ Additionally, they have found applications as active materials for blue electroluminescence. ${ }^{[10]}$ Unlike their red and green counterparts, blue materials have been plagued by several problems due to their intrinsic wide band gap. ${ }^{[11]}$ Moreover, problems of colour purity and quenching due to aggregation, have also been encountered in these materials resulting in low energy emissions. ${ }^{[12]}$

Various design alterations have been explored to counter the aforementioned issues, amongst which star-shaped polycyclic aromatic compounds have emerged as a potential alternative. ${ }^{[13]}$ Truxene, a fluorene based cyclic trimer, has been identified as an excellent building block among the larger polyarenes for organic electronics due to easy chemical engineering. ${ }^{[14]}$ There are several reports of utilizing truxene based star-shaped molecules for OLEDs, ${ }^{[15]}$ OPVs ${ }^{[16]}$ and OFETs ${ }^{[17]}$. However, to construct pure blue emitting materials, bulkier side moieties are required to be coupled with truxene core due to its planar nature. ${ }^{[6 \mathrm{~b}]}$ Alternatively, even larger polyarene systems based on truxene scaffold could be explored to prevent aggregation and to achieve pure emission. ${ }^{[18]}$ Star-shaped materials based on indenofluorene are expected show huge potential as active blue emitting materials. Indenofluorene has been reported to have high fluorescent emission yields along with their emission maxima in the blue region, $410-450 \mathrm{~nm} .{ }^{[19]}$ Additionally, it has been reported that blue emitting compounds based on indenofluorene show better OLED properties in comparison with the fluorene derivatives. ${ }^{[20]}$

In this article, we report the design and synthesis of a novel rigid, blue emitting chromophore based on an extended core of truxene, which is primarily a fused indenofluorene cyclic trimer. We demonstrate that this bulky core can be suitably functionalized to modulate the optical properties of the resultant materials. The photophysical, electrochemical and computational studies of the synthesized materials are presented and their potential for applications in OLEDs as blue emitting materials are discussed.

\section{Results and Discussion}

\section{Synthetic methodology}

The extended core of truxene, ExT was prepared through multistep synthesis as shown in Scheme 1. First, the functionalized truxene core $\mathbf{1}$ was prepared by alkylation and further bromination of truxene with molecular bromine. ${ }^{[6 a, 21]}$ The tribrominated truxene core $\mathbf{1}$ was then utilized as the precursor to carry out Suzuki cross-coupling with methyl 2-(4,4,5,5tetramethyl-1,3,2-dioxaborolan-2-yl)benzoate 2 in the presence of tetrakis(triphenylphosphine)palladium (0) as catalyst, potassium carbonate $\left(\mathrm{K}_{2} \mathrm{CO}_{3}\right)$ as base and tetrahydrofuran (THF) as solvent, to generate trimethyl $2,2^{\prime}, 2^{\prime \prime}-(5,5,10,10,15,15$-hexahexyl-10,15- 
dihydro-5H-diindeno[1,2-a:1',2'-c]fluorene-2,7,12-triyl)tribenzoate

3. The
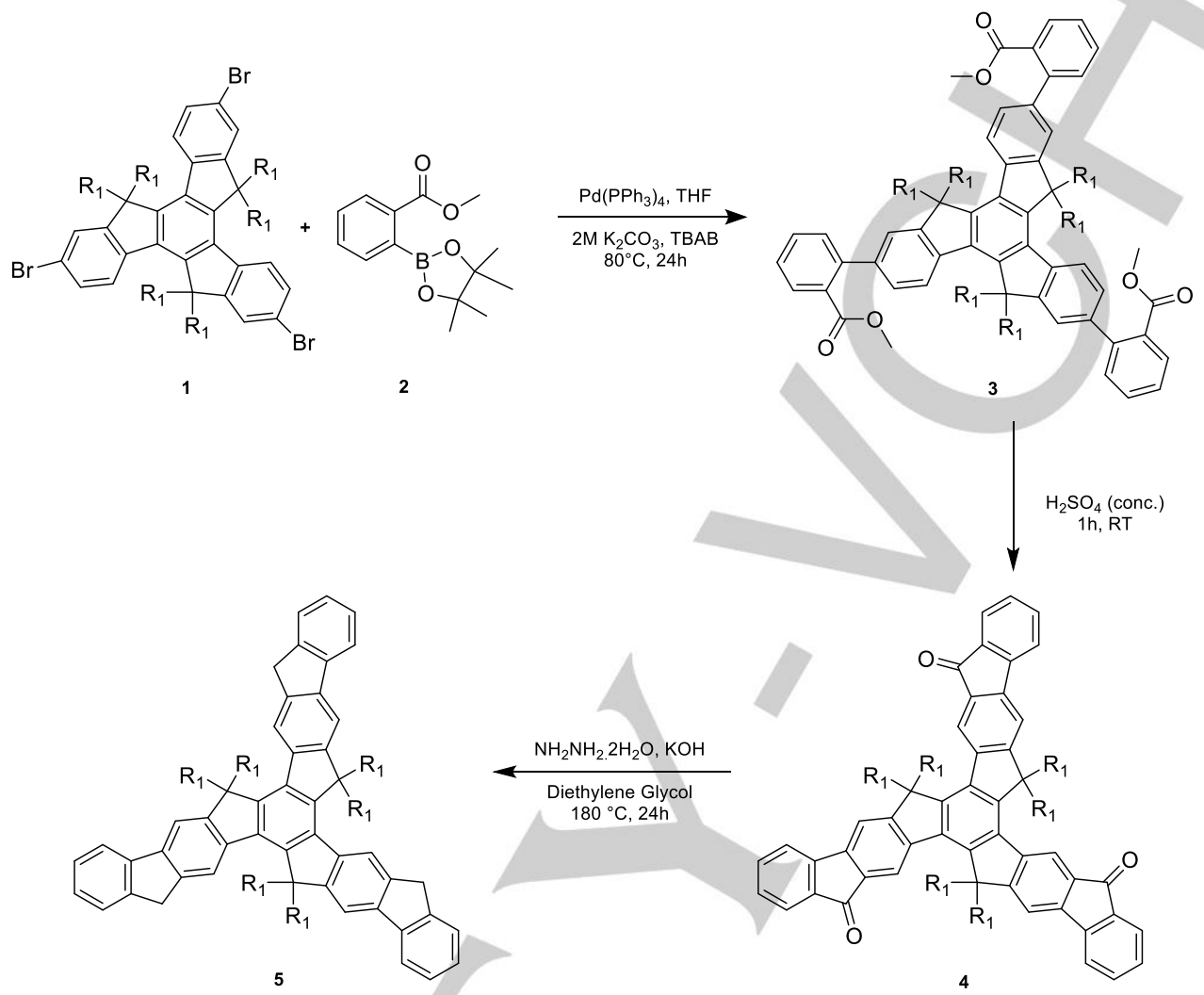

5
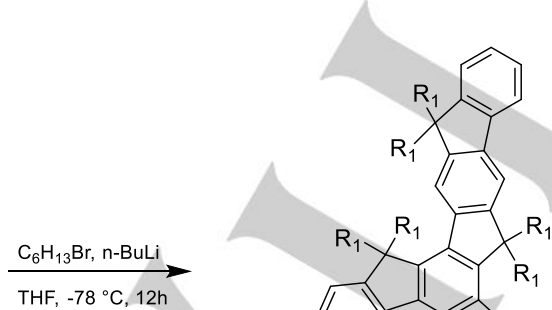

$\mathrm{Br}_{2}, \mathrm{DCM}, \mathrm{RT}, 12 \mathrm{~h}$
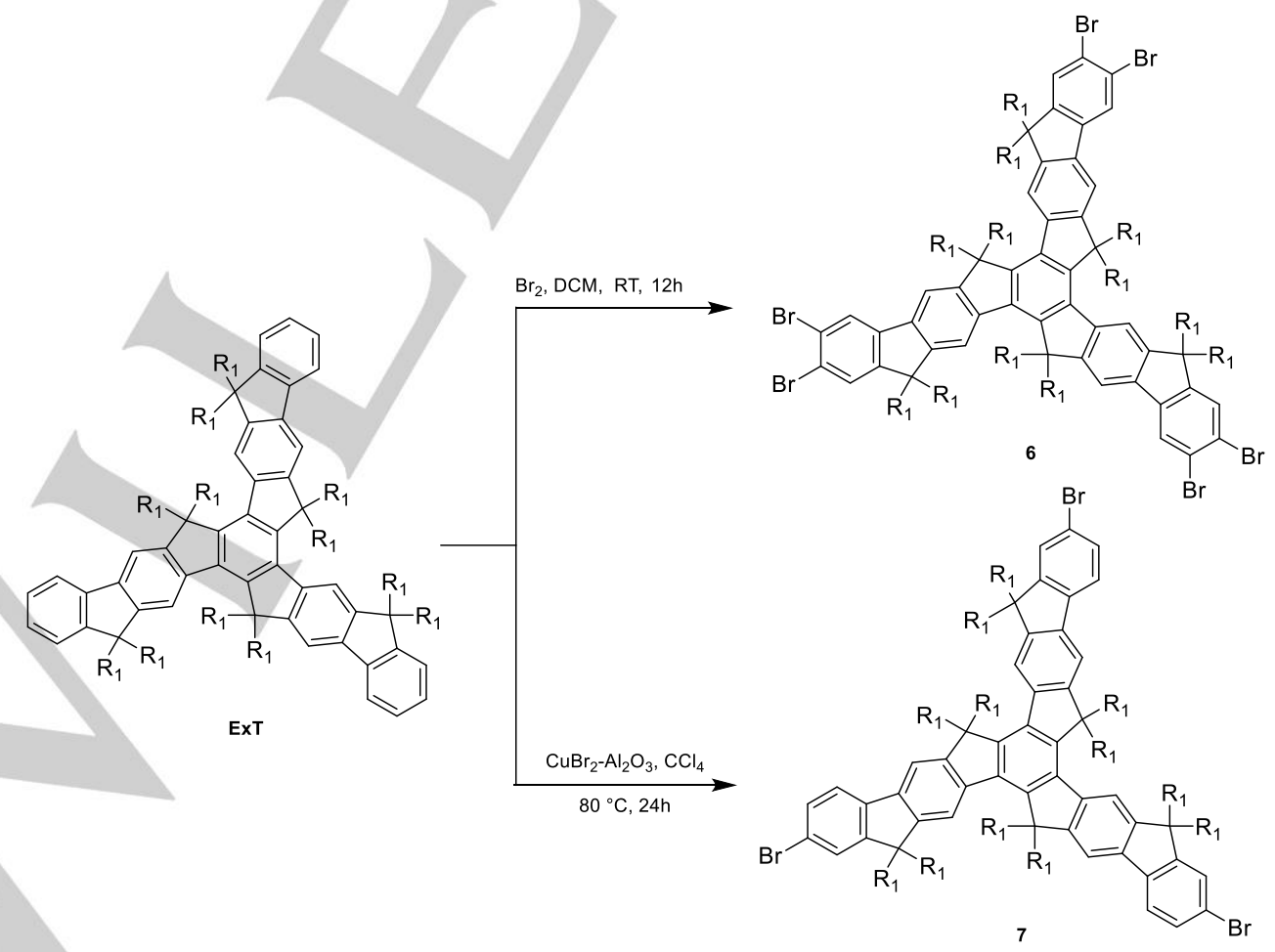

ExT 
Scheme 1. Synthesis of the extended truxene core, ExT and its derivatives 6 and 7.

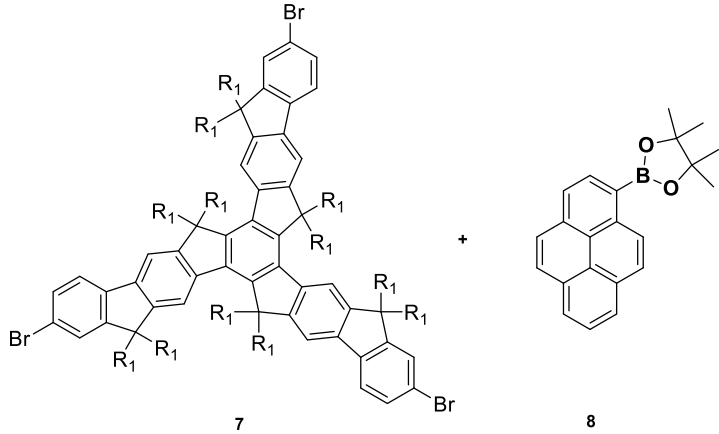

$R_{1}=n-h e x y$

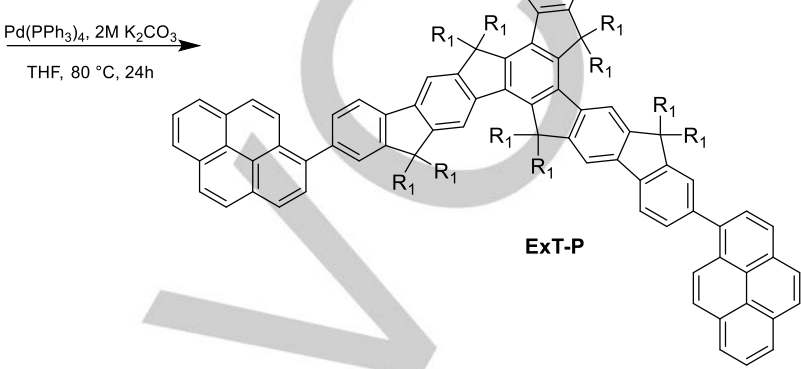

Scheme 2. Synthesis of extended truxene core derived blue emitting ExT-P.

cyclization reaction of $\mathbf{3}$ was carried out in the presence of concentrated sulphuric acid $\left(\mathrm{H}_{2} \mathrm{SO}_{4}\right)$, which resulted in the formation of the intermediate compound 4 . The keto groups present in compound $\mathbf{4}$ were then reduced by Wolff-Kishner reduction reaction in the presence of hydrazine hydrate and diethylene glycol as solvent, to give compound 5. Further alkylation of $\mathbf{5}$ with 1-hexylbromide generated the extended truxene core, ExT. The completely alkylated core, ExT was further functionalized by bromination reaction under different conditions. For bromination, molecular bromine in dichloromethane (DCM) was used to obtain 6 and alternatively, copper(II) bromide adsorbed onto? aluminium oxide $\left(\mathrm{CuBr}_{2-}^{-}\right.$ $\mathrm{Al}_{2} \mathrm{O}_{3}$ ) was used as a selective brominating agent for controlled bromination reaction to obtain the tribrominated derivative of the extended truxene core, 7 . The functionalized precursor 7 was then coupled with boronate ester of pyrene 8 through Suzuki cross-coupling reaction, as shown in Scheme 2, to obtain the target molecule ExT-P. All the compounds and the intermediates

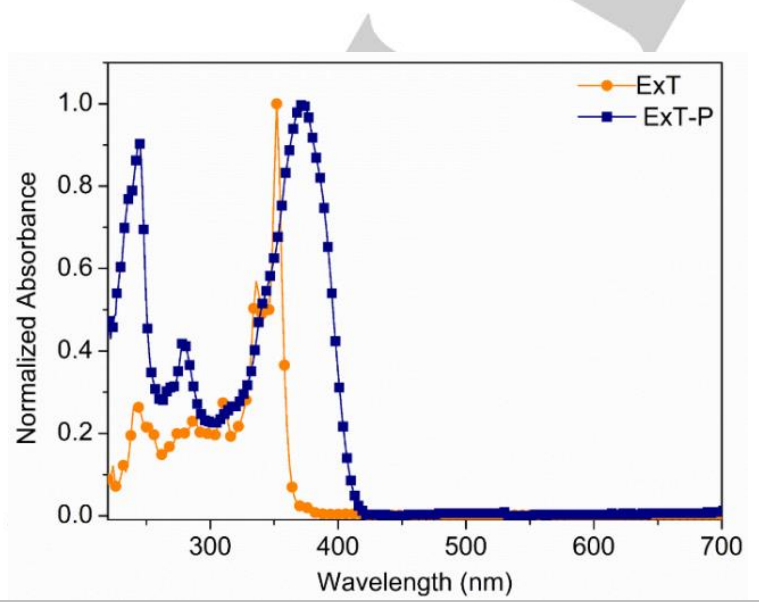

were purified through column chromatography and were characterized by ${ }^{1} \mathrm{H}$ and ${ }^{13} \mathrm{C}$ NMR, and elemental analysis.

Figure 1. The absorbance spectra of the synthesized compounds, ExT and ExT-P, in THF $\left(10^{-5} \mathrm{M}\right)$.

\section{Photophysical studies}

\section{Steady-state spectroscopy and computational studies}

The UV-vis and fluorescence emission spectra of the extended core of truxene based compounds were recorded in THF solution $\left(10^{-5} \mathrm{M}\right)$ and as spin-coated and drop casted $(5 \mathrm{mg} / \mathrm{mL}$ in toluene) films. Figure 1 shows the absorption spectra of the extended core of truxene and the target molecule ExT-P. The high energy peak around $250 \mathrm{~nm}$ is attributed to the $\pi$-system of the truxene scaffold (Table 1). ${ }^{[15 d]}$ The same has also been confirmed theoretically by time dependent density functional theory (TDDFT) studies (Table 2), where electronic transitions show high energy peak at $219 \mathrm{~nm}$ with oscillator strength of 0.2558 (vide infra). Additionally, the peak around $280 \mathrm{~nm}$ in the experimentally obtained absorption spectrum of ExT-P could be attributed to the localized transitions of the pyrene moiety present in the target molecule. ${ }^{[22]}$ The extended core of truxene, ExT gave an absorption maximum at $352 \mathrm{~nm}$, which was found to be redshifted $(\sim 45 \mathrm{~nm})$ when compared with the truxene scaffold. ${ }^{[6 \mathrm{~b}]}$ Theoretically, the TDDFT studies revealed the first transition for ExT at $312 \mathrm{~nm}$ (vide infra). Furthermore, ExT-P exhibits an absorption maximum at $372 \mathrm{~nm}$ due to the extended conjugation obtained upon coupling with pyrene moieties. The TDDFT studies supports this inference, as it revealed a red-shifted maximum for 
ExT-P at $350 \mathrm{~nm}$ with an oscillator strength of 2.6961, when compared to the extended core, ExT.

The time dependent computational studies were carried out to gain further insight into the absorption behaviour of these extended truxene core based molecules. These studies were

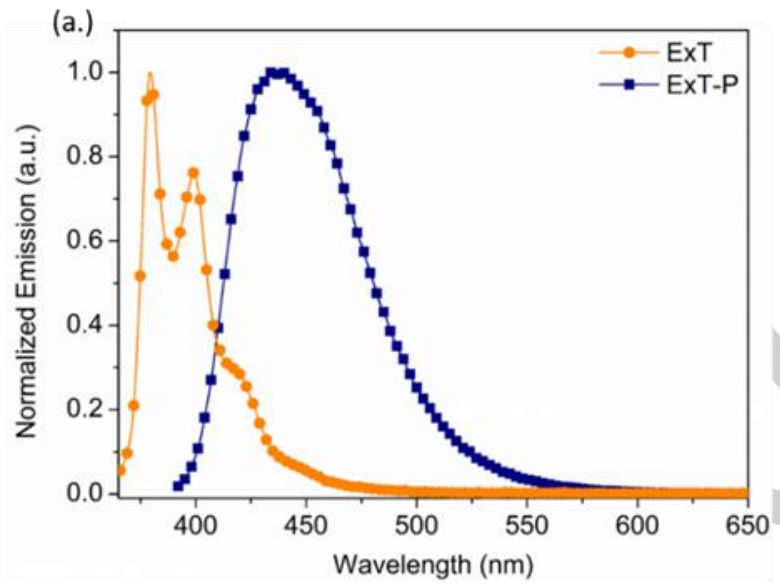

functional theory (DFT) calculations. The DFT studies were performed in the gaseous state, whereas IEFPCM model was used for THF solvent for performing TDDFT. The optimized geometries of the compounds ExT and ExT-P are shown in Figure 3 with their electron density distributions in the highest

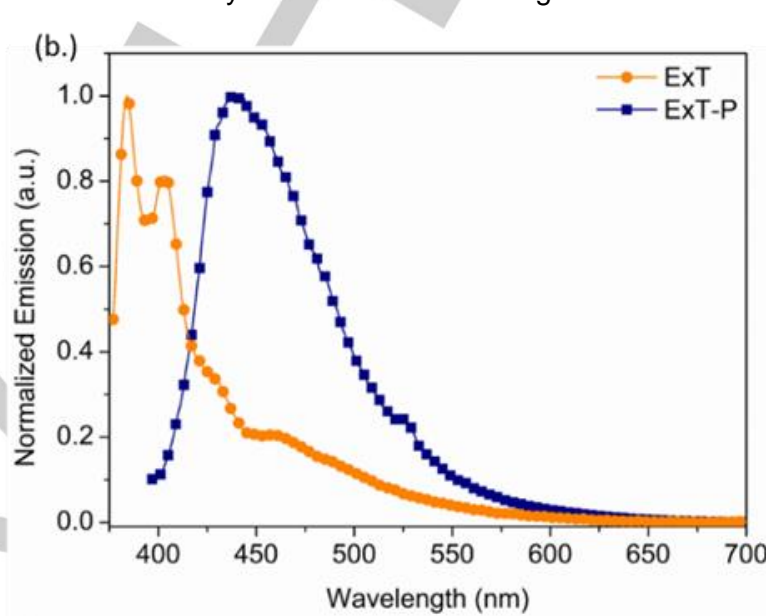

performed on the optimized geometries obtained from density occupied molecular orbital (HOMO) and lowest unoccupied

Figure 2. The emission spectra of ExT and ExT-P (a.) in solution, inset showing emission under long wavelength UV-vis (10-5 M) (b.) in thin film.

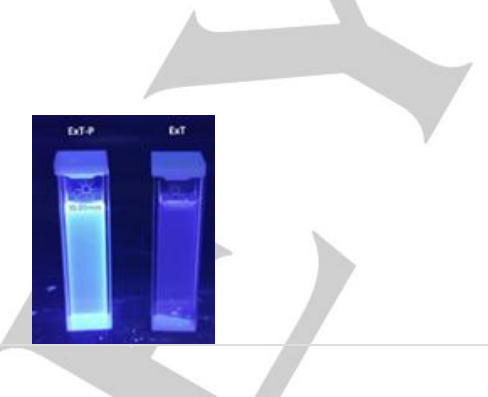

\begin{tabular}{|c|c|c|c|c|c|c|}
\hline \multirow{2}{*}{ Compound } & \multicolumn{2}{|c|}{ Solution } & \multicolumn{2}{|c|}{ Film } & \multirow{2}{*}{$\lambda_{\text {edge }}(\mathrm{nm})$} & \multirow{2}{*}{$\Phi_{\mathrm{F}}$} \\
\hline & $\lambda^{\mathrm{abs}}(\mathrm{nm})$ & $\lambda^{\mathrm{emis}}(\mathrm{nm})$ & $\lambda^{\mathrm{abs}}(\mathrm{nm})$ & $\lambda^{\mathrm{emis}}(\mathrm{nm})$ & & \\
\hline ExT & 242,352 & 398 & 368 & 403 & 392 & $0.18(0.10)$ \\
\hline ExT-P & $243,282,372$ & 441 & 378 & 442 & 445 & $0.97(0.29)$ \\
\hline
\end{tabular}

molecular orbital (LUMO) levels shown in Figure 4. The time dependent computations were used to obtain the values of possible vertical transition energies, their contribution and oscillator strengths (Table 2). In case of the molecule ExT, the TDDFT studies revealed the first transition at $312 \mathrm{~nm}$, showing its major contribution from the HOMO $\rightarrow$ LUMO transition and oscillator strength of 2.0714 . This value can be correlated with the experimental absorption maximum value of $352 \mathrm{~nm}$. In case of the compound ExT-P, the first energy transition from TDDFT studies was observed at $350-347 \mathrm{~nm}$ which could be attributed to $\pi-\pi-$ transition of truxene. This transition showed major contribution from $\mathrm{HOMO} \rightarrow$ LUMO, with its oscillator strength values corresponding to 2.6961 and 0.6123 , respectively. The computationally simulated absorption spectra of the compounds are shown in Figure S2 (Supplementary information).

The emission spectra of the compounds in solution $\left(10^{-5} \mathrm{M}\right)$ and as thin film are shown in Figure 2. The emission spectrum of the extended core of truxene shows vibronic features. However, a broad and featureless emission spectrum was obtained in the case of the target molecule ExT-P. In solution, the emission for 
ExT-P is red-shifted compared to the rigid extended core of truxene with its emission maximum at $441 \mathrm{~nm}$ (Table 1). Furthermore, in the solid state the emission maximum of the extended core of truxene is slightly red shifted due to its planar structure. However, the solid state emission maxima of ExT-P was obtained at $442 \mathrm{~nm}$, with a minor red shift of $\sim 1 \mathrm{~nm}$ attributable to the non-planarity induced into the molecular system by incorporation of the pyrene groups as side moieties and additionally to the larger and rigid extended truxene moiety at the core. A similar inference can be drawn while comparing the emission maxima of truxene-pyrene conjugate, in both solution and solid-state, as reported in our earlier report. ${ }^{[23]}$ While moving from the solution to solid-state spectrum of truxene-pyrene conjugate, a large red-shift of $42 \mathrm{~nm}$ and peak-broadening was obtained, attributable to aggregation, whereas in the case of ExTP, this shift was very minor $(\sim 1 \mathrm{~nm}){ }^{\left[{ }^{23-24]}\right.}$ Furthermore, the full width-half maximum (FWHM) value of solid-state emission in ExT-P was found to be $75.9 \mathrm{~nm}$, a much lower value when compared to FWHM value of the previously reported truxenepyrene conjugate $(111.9 \mathrm{~nm}) .{ }^{[23]}$ The lower FWHM value suggests better colour purity for ExT-P in solid state emission. ${ }^{[25]}$ The

a.)

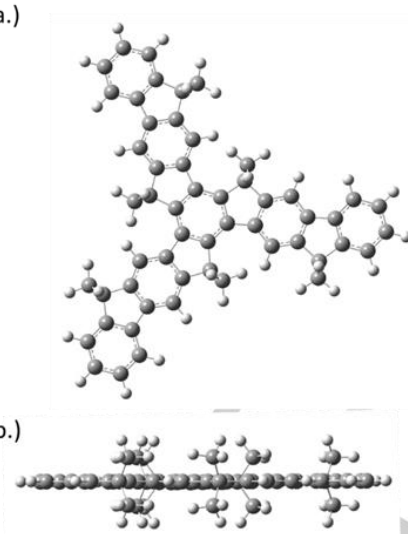

computational studies also support the experimental data obtained from solid-state emission. The extended truxene core, ExT was found to be planar in nature, similar to its truxene precursor. ${ }^{[6]}$ However, the target compound, ExT-P with pyrenyl moieties was found to be non-planar in nature with a dihedral angle of $54^{\circ}$ (Figure 3). Even though, the dihedral angle of ExT$\mathbf{P}$ was found to be similar to its truxene-pyrene based analogue, reported in our previous report, the solid state emission of the ExT-P suggests no aggregation unlike the truxene-pyrene conjugate, reinforcing the assertion that the presence of a bulkier core and additional hexyl chains help in preventing the aggregation in solid-state. Therefore, while keeping the side moieties same, but changing the core to bulky and much rigid molecular system, the aggregation in solid-state can be prevented. ${ }^{[18,26]}$ The photoluminescence quantum yield, $\Phi_{\mathrm{F}}$ (PLQY) of the compounds ExT and ExT-P was recorded in both solution and solid-state. In (THF) solution, the PLQY values were found to be 0.18 and 0.97 for ExT and ExT-P, respectively, whereas in toluene drop casted films the values obtained were 0.10 and 0.29 for ExT and ExT-P, respectively.

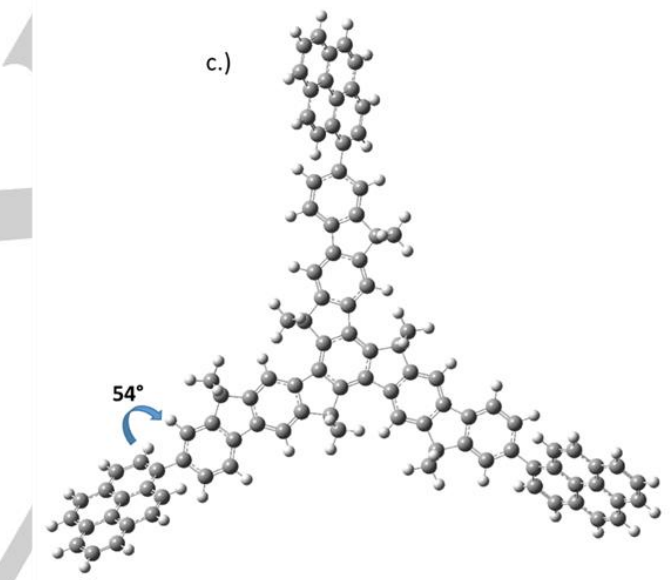

Figure 3. Optimized geometries of the molecules (a.) ExT, (b.) planar view of the ExT core, with alkyl groups sticking out, (c.) ExT-P.

Table 2. The representative wavelengths and the oscillator strength values obtained from time-dependent studies

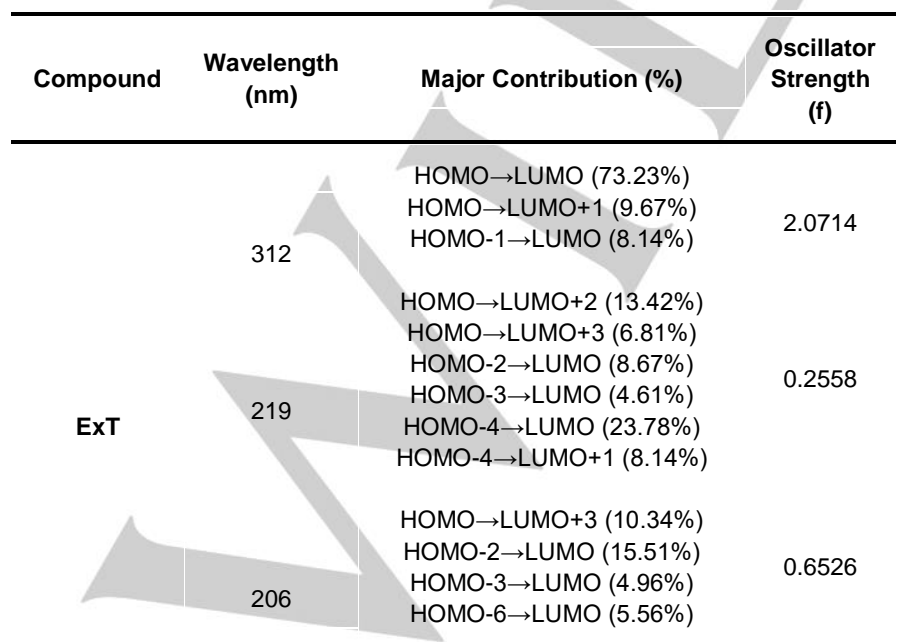




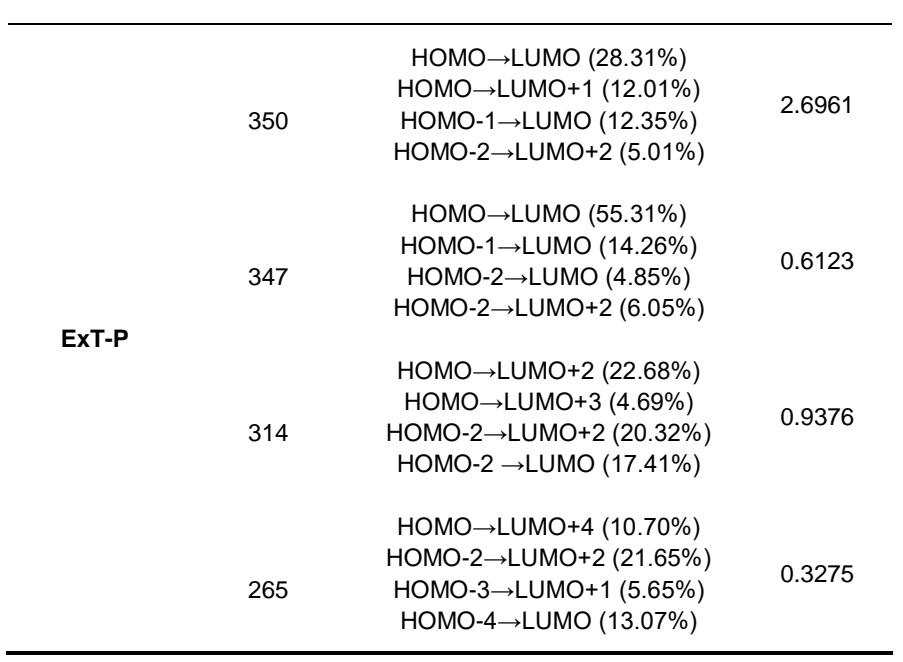

\section{Transient absorption spectroscopy}

The excited state spectra and dynamics of both ExT and ExT-P were monitored by transient absorption (TA) spectroscopy. ${ }^{[27]}$ Figures 5a-b show the nanosecond-microsecond (ns- $\mu \mathrm{s})$ TA spectra and dynamics of ExT after excitation at $355 \mathrm{~nm}$, measured in degassed solution. Note that the TA signal is negative for photo-induced absorption (PA) and positive in the case of the photo-bleach (PB). The singlet states (black line, panel b) are created instantaneously (within the laser pump pulse duration) and then decay within several tens of nanoseconds. A slight red shift of the peak of the PA to $450 \mathrm{~nm}$ is observed at early times, indicating the generation of longerlived triplet excited states, likely via intersystem crossing (ISC) of singlet states. The band prominent at $750 \mathrm{~nm}$ is assigned to the singlet excited states and the bands at $450 \mathrm{~nm}$ and $650 \mathrm{~nm}$ represent the features of triplet excited states, however, convoluted with the singlet-induced absorption at early delay times. Figure $5 \mathbf{b}$ shows the normalized integrated kinetics of selected spectral regions of panel (a) as indicated in the legend. The dynamics at 460-475 $\mathrm{nm}$ (green line, assigned to triplet states) show no signal decay until $1 \mu \mathrm{s}$, while the dynamics monitored at $850-890 \mathrm{~nm}$ (black line, assigned to singlets) decay entirely within tens of nanoseconds. The strong signal amplitude remaining at 100 s of nanosecond delays times implies that a significant amount of singlet states have been converted into long-lived triplets via ISC in this system.

To further quantify the rate of the generation and decay dynamics of the excited states, we performed multivariate curve resolution alternating least squares (MCR-ALS) data analysis method of the data obtained by TA spectroscopy. MCR-ALS is a soft modeling tool introduced earlier by Tauler et al. and previously used by us and others to analyse TA data. ${ }^{[27-28]}$ Figure 5c represents the de-convoluted kinetics of excited states of ExT as obtained from MCR-ALS (for MCR-ALS spectra, see Figure S1). As seen in Figure 5c, the decay of single
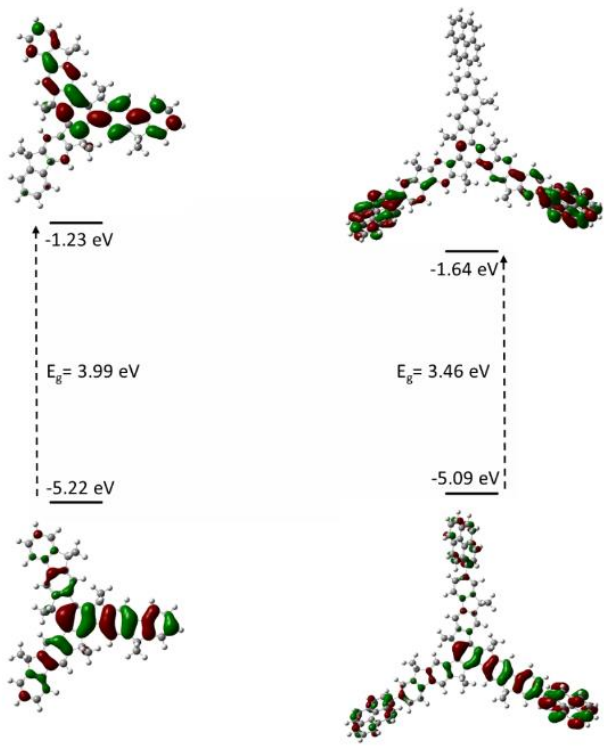

states for ExT is relatively slow (black open circles) and yields an inverse decay rate constant of $17 \mathrm{~ns}$. All inverse rate constants are obtained by exponential fits (solid lines) to the MCR-ALS kinetics. In line with the singlet state decay, the triplet state generation shows an inverse rate constant of $16 \mathrm{~ns}$.
Figure 4 The HOMO-LUMO distributions of the target molecules ExT and ExT-P

The lower panels of Figure 5 represent the nanosecondmicrosecond TA spectra (c) and kinetics (d) of the target molecule ExT-P. The spectral position of the singlet states is virtually similar to that of ExT, however, the triplet-induced absorption spectrum is very different (see the inset of $(d)$ ). We note that more than $\sim 90 \%$ of the singlet state population decayed in 7-8 ns, as the signal at $750 \mathrm{~nm}$ implies (black line in panel e), while generating only few triplet states, as indicated by the weak remaining tripletinduced absorption signal. For comparison, in the case of ExT, the respective decay is only

$\sim 24 \%$ of the signal amplitude at $10 \mathrm{~ns}$. This is in good agreement with the high fluorescence quantum yield observed for ExT-P, indicating that non-radiative processes are reduced and most states recombine radiatively. In fact, PLQY measurements showed 0.97 quantum yield in solution, which is significantly higher than 0.18 obtained for ExT. Unlike in ExT, the MCR-ALS analysis of ExT-P show nanosecond singlet decay ( 1.6 ns) and corresponding triplet generation dynamics ( 2.3 ns). However, we note that these values are close to our temporal resolution. We further note that, as seen from the Figure 5d,e, 90\% singlets decayed without generating any triplet states. These results clearly indicate that the extended core of the target molecule enhances the radiative singlet state decay leading to strong fluorescence and thus inhibits triplet formation via ISC. 

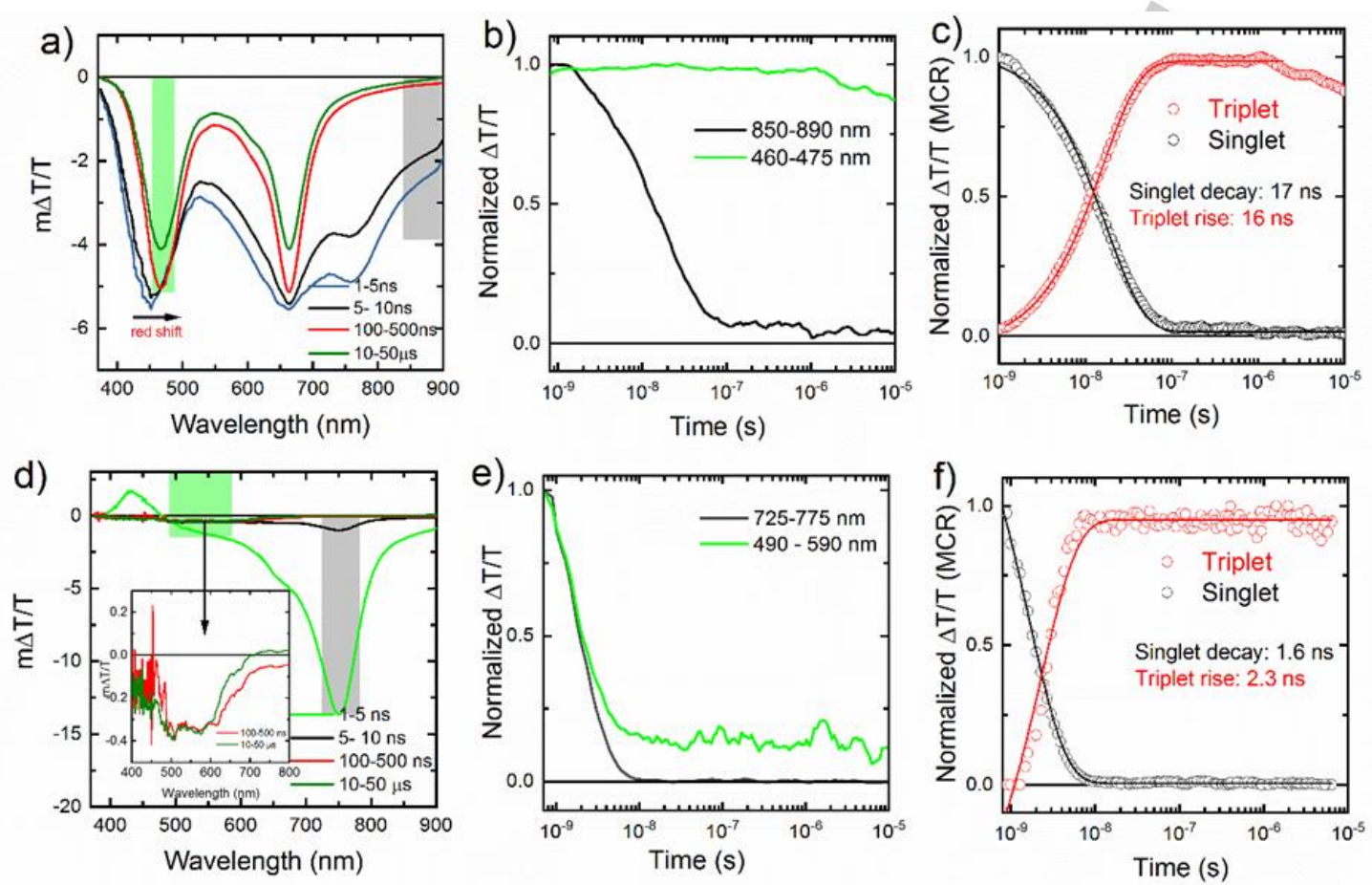

Figure 5. a) Nanosecond-microsecond TA spectra of ExT in THF b) Nanosecond-microsecond excited state dynamics of selected spectra regions of (a). c) The kinetics obtained from MCR-ALS analysis for ExT. The solid lines represent the exponential fit to the MCR-ALS data. d,e) The nanosecond-microsecond spectra and excited state dynamics of target molecule ExT-P. f) The kinetics obtained from MCR-ALS analysis for ExT-P.

\begin{tabular}{|c|c|c|c|c|c|c|c|}
\hline Compound & $\mathrm{E}_{\text {номо }}{ }^{[\mathrm{a}]}(\mathrm{eV})$ & $E_{\text {LUMO }}{ }^{[a]}(e V)$ & $E_{g}^{o p t}(e V)$ & $\mathrm{E}_{\text {номо }}{ }^{[\mathrm{b}]}(\mathrm{eV})$ & $\mathrm{E}_{\text {LUMO }^{[b]}}(\mathrm{eV})$ & $E_{g}^{[b]}(e V)$ & $E_{g}[c](e V)$ \\
\hline ExT & -4.98 & -1.81 & 3.17 & -5.22 & -1.23 & 3.99 & $3.97\left(3.18^{[\mathrm{d}]}\right)$ \\
\hline ExT-P & -5.45 & -2.61 & 2.84 & -5.10 & -1.64 & 3.49 & $3.53\left(2.79^{[\mathrm{d}]}\right)$ \\
\hline
\end{tabular}

[a] experimental values using CV [b] obtained using DFT calculations [c] obtained from time-dependent studies [d] obtained from vertical optical gap by TDDFT

\section{Electrochemical studies}

The electrochemical properties of the compounds based on the extended truxene core were studied by cyclic voltammetry. The cyclic voltammograms (Figure S3) were used to estimate the HOMO energy levels of the compounds. The onset of the oxidation potential of the extended truxene core ExT was found to be much lower than the target molecule ExT-P, suggesting higher oxidative stability of the target molecule. The HOMO energy level of the target molecule ExT-P was found to be matching well with ITO and PEDOT:PSS. The LUMO energy levels were estimated from the HOMO energy levels and the optical bad gap, $E_{g}{ }^{\text {opt. [29] }}$ The optical band gap values were obtained from the onset of the absorption and were observed at $3.17 \mathrm{eV}(392 \mathrm{~nm})$ for the extended core and at $2.84 \mathrm{eV}(445 \mathrm{~nm})$ for ExT-P (Table 3). Therefore, the value of the LUMO energy level was found to be $-1.81 \mathrm{eV}$ for the extended truxene core whereas the target molecule ExT-P showed a comparatively deeper LUMO value at $-2.61 \mathrm{eV}$. The computationally obtained band gap values from DFT studies for the HOMO-LUMO energy levels for ExT and ExT-P were found to be $3.99 \mathrm{eV}$ and $3.46 \mathrm{eV}$, respectively. The experimentally obtained HOMO level of ExT-P was found to be much lower than the computationally obtained 
value when compared to ExT as the DFT computational studies do not consider the role of the solvent. ${ }^{[30]}$ Additionally, the band gap values were also obtained from the TDDFT studies as shown in Table 3. The band gap values obtained from the lowest singlet excited state transition energies closely matched with the experimental values. ${ }^{[31]}$

\section{Conclusions}

A novel, rigid and extended core of truxene was designed and synthesized as a potential blue emitting chromophore. The additional methylene bridges in the extended core can be easily alkylated to render it and its derivatives readily solution processable. This core can be readily and selectively brominated making it an attractive core for further functionalization. This was demonstrated by the introduction of three pyrene substituents symmetrically substituted along the periphery to synthesize ExTP. UV-vis absorption studies of the extended core showed its absorption maximum at $352 \mathrm{~nm}$ showing a bathochromic shift when compared to the truxene core due to the extended $\pi$ conjugation. The pyrene derivative, ExT-P showed emission maximum at $441 \mathrm{~nm}$ in THF solution revealing its blue emitting nature with high PLQY value of 0.97 and optical band gap value at $2.84 \mathrm{eV}$. The solid state emission spectra of both the extended core ExT and target molecule ExT-P showed very minor to negligible red shift revealing negligible aggregation, even with the planar structure of the ExT. Besides, TA studies on the molecules in solution demonstrated shorter singlet state lifetimes of the pyrene coupled ExT-P molecule and significantly less triplet state formation. Altogether, the results suggest that the extended core coupled with pyrene might show improved electroluminescence in devices due to the presence of the highly fluorescent pyrene moiety. Beyond the materials presented in here, the selective functionalization of the core paves the path for development of pure blue emitting materials through cross-coupling reactions. Therefore, it can be concluded that the extended core of truxene prevents aggregation in the solid state due to its much bulkier and rigid structure and highlights the potential for the use of this core derived materials as blue emitters.

\section{Experimental Section}

\section{Methods and materials}

All the chemicals used for synthesis were obtained from Merck, and Spectrochem and Sigma Aldrich. The chemicals were used without further purification, unless mentioned otherwise. ${ }^{1} \mathrm{H}$ and ${ }^{13} \mathrm{C}$ NMR spectra were recorded on a Bruker Avance III $400 \mathrm{MHz}$ spectrometer. The absorption spectra were recorded on T90+ UV-vis spectrophotometer. PL studies were done using Agilent Cary Eclipse fluorescence spectrophotometer. The PLQY of the solutions were recorded through relative method where anthracene was used as the standard $\left(\Phi_{\mathrm{F}}=0.27\right.$, in ethanol). ${ }^{[32]}$ The PLQY of the thin films drop casted in toluene $\left(5 \mathrm{mg} / \mathrm{mL}\right.$, annealed at $\left.60^{\circ} \mathrm{C}\right)$ were obtained by using an Edinburgh Instruments integrating sphere with a FLS920 fluorescence spectrometer. Cyclic voltammograms of the compounds were obtained using Biologic-SP 150 electrochemical quartz crystal microbalance with $0.1 \mathrm{M}$ tetrabutylammonium perchlorate as the supporting electrolyte at room temperature. The computational studies on the synthesized compounds were performed utilizing Gaussian 09 package using the basis set B3LYP at 6-31G (d,p) level.[33] The computation time was reduced by replacing the hexyl chains with methyl groups in the molecules.

\section{Transient absorption spectroscopy}

TA spectroscopy was carried out on blend films using a homebuilt pumpprobe setup. The output of a titanium:sapphire amplifier (Coherent LEGEND DUO, $4.5 \mathrm{~mJ}, 3 \mathrm{kHz}, 100 \mathrm{fs})$ was split into three beams (2, 1, and $1.5 \mathrm{~mJ}$ ). Two of them were used to separately pump two optical parametric amplifiers (OPA) (Light Conversion TOPAS Prime). TOPAS 1 generates tunable pump pulses for picosecond-nanosecond TA spectroscopy, while TOPAS 2 generates signal $(1300 \mathrm{~nm})$ and idler $(2000$ $\mathrm{nm}$ ) only. TOPAS 2 was used to produce a white-light super continuum from 350 to $1100 \mathrm{~nm}$ by sending the $1300 \mathrm{~nm}$ pulses through a calcium fluoride $\left(\mathrm{CaF}_{2}\right)$ crystal which is mounted on continuously moving stage.

For the $1 \mathrm{~ns}$ to $10 \mu \mathrm{s}$ delay (long delay) TA measurements, the excitation light (pump pulse) was provided by an actively Q-switched $\mathrm{Nd}: \mathrm{YVO}_{4}$ laser (InnoLas picolo AOT) frequency-doubled to provide pulses at $532 \mathrm{~nm}$ and $355 \mathrm{~nm}$. The pump laser was triggered by an electronic delay generator (Stanford Research Systems DG535) itself triggered by the transistortransistor logic (TTL) sync from the Legend DUO, allowing control of the delay between pump and probe with a jitter of roughly 100 ps. Pump and probe beams were focused on the sample which was kept under a dynamic vacuum of $<10-5$ mbar. The transmitted fraction of the white light was guided to a custom-made prism spectrograph (Entwicklungsbüro Stresing) where it was dispersed by a prism onto a 512 pixel complementary metal-oxide semiconductor (CMOS) linear image sensor (Hamamatsu G11608-512DA). The probe pulse repetition rate was $3 \mathrm{kHz}$, while the excitation pulses were directly generated at $1.5 \mathrm{kHz}$ frequency (1 ns to $10 \mu$ s delays), while the detector array was read out at $3 \mathrm{kHz}$. Adjacent diode readings corresponding to the transmission of the sample after excitation and in the absence of an excitation pulse were used to calculate $\Delta T / T$. Measurements were averaged over several thousand shots to obtain a good signal-to noise ratio. The chirp induced by the transmissive optics was corrected with a homebuilt Matlab code. The delay at which pump and probe arrive simultaneously on the sample (i.e., zero time) was determined from the point of maximum positive slope of the TA signal rise for each wavelength.

\section{Synthesis}

The compounds 2,7,12-tribromo-5,5',10,10',15,15'-hexahexyltruxene (1), methyl 2-(4,4,5,5-tetramethyl-1,3,2-dioxaborolan-2-yl)benzoate (2) and 4,4,5,5-tetramethyl-2-(pyren-1-yl)-1,3,2-dioxaborolane (3) were prepared according to the literature. ${ }^{[21 b, 34]}$

\section{Synthesis of compound 3}

To a solution of $1(0.50 \mathrm{~g}, 0.46 \mathrm{mmol})$ and methyl 2-(4,4,5,5-tetramethyl1,3,2-dioxaborolan-2-yl)benzoate $(0.44 \mathrm{~g}, 1.66 \mathrm{mmol})$ in $4.6 \mathrm{~mL} \mathrm{THF}$ $\mathrm{Pd}\left(\mathrm{PPh}_{3}\right)_{4} \quad(0.043 \mathrm{~g}, 8 \mathrm{~mol} \%)$ was added along with $1 \mathrm{~mL}$ of $2 \mathrm{M} \mathrm{K}_{2} \mathrm{CO}_{3}$ and tetrabutylammoniumbromide (TBAB), with continuous stirring. The reaction mixture was heated to $80^{\circ} \mathrm{C}$ for 24 hours in nitrogen atmosphere. On completion, the reaction mixture was extracted with chloroform. The organic phase was washed with water and dried over sodium sulphate. The solvent was evaporated and the residue was purified using column chromatography. The product was obtained as a white solid $(0.39 \mathrm{~g}, 68 \%)$. ${ }^{1} \mathrm{H}$ NMR $\left(400 \mathrm{MHz}, \mathrm{CDCl}_{3}\right): \delta 8.39(\mathrm{~d}, J=8.2 \mathrm{~Hz}, 3 \mathrm{H}), 7.84(\mathrm{~d}, J=7.5 \mathrm{~Hz}$, $3 \mathrm{H}), 7.61-7.53(\mathrm{~m}, 6 \mathrm{H}), 7.47-7.42(\mathrm{~m}, 6 \mathrm{H}), 7.35(\mathrm{~d}, J=7.7 \mathrm{~Hz}, 3 \mathrm{H}), 3.59$ 
(s, 9H), 3.04-2.97 (m, 6H), 2.14-2.07 (m, 6H), 0.97-0.84 (m, 36H), $0.61(\mathrm{t}$, $J=7.08 \mathrm{~Hz}, 30 \mathrm{H}) .{ }^{13} \mathrm{C}$ NMR $\left(75 \mathrm{MHz}, \mathrm{CDCl}_{3}\right): \delta 169.80,153.51,145.18$, 142.39, 139.51, 138.13, 131.53, 131.10, 130.63, 129.61, 127.06, 126.34, 124.31, 122.21, 55.77, 51.65, 37.03, 31.91, 29.68, 23.98, 22.28, 14.09. Anal. calcd for $\mathrm{C}_{87} \mathrm{H}_{108} \mathrm{O}_{6}$ : C, 83.61; $\mathrm{H}, 8.71$. Found: $\mathrm{C}, 83.43 ; \mathrm{H}, 8.66$.

\section{Synthesis of compound 4}

The substrate $3(0.39 \mathrm{~g}, 0.32 \mathrm{mmol})$ was cyclized in the presence of $\mathrm{H}_{2} \mathrm{SO}_{4}$ (conc.), by stirring the mixture at room temperature for 1 hour. The reaction mixture was diluted with water and was extracted with chloroform. The solvent was then evaporated and the residue was purified using column chromatography to obtain the purified product as a yellow coloured solid (0.32 g, 89\%). ${ }^{1} \mathrm{H}$ NMR $\left(400 \mathrm{MHz}, \mathrm{CDCl}_{3}\right): \delta 8.63(\mathrm{~s}, 3 \mathrm{H}), 7.74$ (d, $J=7.5$ $\mathrm{Hz}, 3 \mathrm{H}), 7.69(\mathrm{~d}, J=7.4 \mathrm{~Hz}, 3 \mathrm{H}), 7.63(\mathrm{~s}, 3 \mathrm{H}), 7.56\left(\mathrm{dt}, J_{a}=7.5 \mathrm{~Hz}, J_{b}=\right.$ $0.9 \mathrm{~Hz}, 3 \mathrm{H}), 7.34(\mathrm{t}, J=6.8 \mathrm{~Hz}, 3 \mathrm{H}), 3.03-2.96(\mathrm{~m}, 6 \mathrm{H}), 2.25-2.17(\mathrm{~m}, 6 \mathrm{H})$, $0.98-0.80(\mathrm{~m}, 36 \mathrm{H}), 0.59-0.55(\mathrm{~m}, 30 \mathrm{H}) .{ }^{13} \mathrm{C} \mathrm{NMR}\left(75 \mathrm{MHz}, \mathrm{CDCl}_{3}\right): \delta$ $193.74,161.97,145.58,144.63,143.64,140.76,137.80,135.55,134.82$, $133.77,129.15,124.42,120.70,120.51,114.66,56.54,37.06,31.61$, 29.52, 24.29, 22.37, 13.95. Anal. calcd for $\mathrm{C}_{84} \mathrm{H}_{96} \mathrm{O}_{3}: \mathrm{C}, 87.45 ; \mathrm{H}, 8.39$. Found: C, 87.23; H, 8.53 .

\section{Synthesis of compound 5}

Reduction reaction of $4(0.20 \mathrm{~g}, 0.17 \mathrm{mmol})$ was carried out by WolffKishner reaction by adding hydrazine hydrate $(0.34 \mathrm{~mL}, 6.94 \mathrm{mmol})$, using $\mathrm{KO}{ }^{\mathrm{B}} \mathrm{Bu}(0.39 \mathrm{~g}, 3.47 \mathrm{mmol})$ as the base and diethylene glycol $(1.75 \mathrm{~mL})$ as solvent at $190{ }^{\circ} \mathrm{C}$. The reaction was monitored using TLC and upon complete consumption of the reactants, it was extracted from hexane. The crude product was purified using column chromatography to obtain yellow solid (0.09 g, 45\%). ${ }^{1} \mathrm{H} \mathrm{NMR}\left(400 \mathrm{MHz}, \mathrm{CDCl}_{3}\right): \delta 8.58(\mathrm{~s}, 3 \mathrm{H}), 7.94$ (d, $J=$ $7.3 \mathrm{~Hz}, 3 \mathrm{H}), 7.86(\mathrm{~s}, 3 \mathrm{H}), 7.62(\mathrm{~d}, J=7.0 \mathrm{~Hz}, 3 \mathrm{H}), 7.44(\mathrm{t}, J=7.0 \mathrm{~Hz}, 3 \mathrm{H})$, $7.34(\mathrm{t}, J=7.2 \mathrm{~Hz}, 3 \mathrm{H}), 4.11(\mathrm{~s}, 6 \mathrm{H}), 3.08-3.07(\mathrm{~m}, 6 \mathrm{H}), 2.23-2.21(\mathrm{~m}, 6 \mathrm{H})$, 0.89-0.85 (m, 36H), 0.59-0.54 (m, 30H). ${ }^{13} \mathrm{C} \mathrm{NMR}\left(75 \mathrm{MHz}, \mathrm{CDCl}_{3}\right): \delta$ 153.33, 144.97, 144.21, 142.12, 141.58, 140.31, 139.81, 138.74, 126.89, $126.57,125.25,121.25,119.99,113.44,55.48,37.76,37.41,31.59,29.85$, $24.19,22.44,14.01$. Anal. calcd for $\mathrm{C}_{84} \mathrm{H}_{102}: \mathrm{C}, 90.75 ; \mathrm{H}, 9.25$. Found: $\mathrm{C}$ 90.38; H, 9.23 .

\section{Synthesis of compound ExT}

To a solution of compound $5(0.40 \mathrm{~g}, 0.36 \mathrm{mmol})$ in $3.7 \mathrm{~mL}$ THF at $-78^{\circ} \mathrm{C}$, n-BuLi (3.4 mL, $5.40 \mathrm{mmol}$ ) was added dropwise under nitrogen atmosphere. The stirring was continued for 2 hours and then 1 bromohexane $(0.56 \mathrm{~mL}, 5.40 \mathrm{mmol})$ was added. The reaction was continued overnight at room temperature. Upon completion, it was extracted with hexane and organic layer was washed several times with brine and water. The residue was purified by column chromatography over silica gel using hexane as eluent to obtain white coloured solid $(0.34 \mathrm{~g}$, $58 \%) .{ }^{1} \mathrm{H} \mathrm{NMR}\left(400 \mathrm{MHz}, \mathrm{CDCl}_{3}\right): \delta 8.42(\mathrm{~s}, 3 \mathrm{H}), 7.84(\mathrm{~d}, J=7.2 \mathrm{~Hz}, 3 \mathrm{H})$, $7.79(\mathrm{~s}, 3 \mathrm{H}), 7.41(\mathrm{t}, J=7.6 \mathrm{~Hz}, 6 \mathrm{H}), 7.36-7.29(\mathrm{~m}, 3 \mathrm{H}), 3.15-3.08(\mathrm{~m}, 6 \mathrm{H})$, 2.35-2.28 (m, 6H), 2.09-2.18 (m, 12H), 0.87-0.83 (m, 42H), $0.73(\mathrm{~m}, 36 \mathrm{H})$, $0.61(\mathrm{~m}, 24 \mathrm{H}), 0.56-0.54(\mathrm{~m}, 30 \mathrm{H}) .{ }^{13} \mathrm{C}$ NMR $\left(100 \mathrm{MHz}, \mathrm{CDCl}_{3}\right): \delta 153.26$ $151.65,148.95,144.65,141.64,139.85,139.71,138.89,126.86,123.00$, $119.66,119.15,114.22,113.21,55.4754 .97,41.31,37.69,33.99,32.09$, $31.84,30.25,29.53,29.12,24.24,22.80,22.38,14.11$. Anal. calcd for $\mathrm{C}_{120} \mathrm{H}_{174} \mathrm{O}_{6}: \mathrm{C}, 89.15 ; \mathrm{H}, 10.85$. Found: $\mathrm{C}, 88.65 ; \mathrm{H}, 10.91$.

\section{Synthesis of compound 6}

To a solution of ExT $(0.10 \mathrm{~g}, 0.06 \mathrm{mmol})$ in DCM $(0.4 \mathrm{~mL})$, molecular bromine $(0.01 \mathrm{~mL}, 0.18 \mathrm{mmol})$ dissolved in DCM was added dropwise at $0{ }^{\circ} \mathrm{C}$. The reaction was continued for 24 hours at room temperature. Upon the completion of the reaction, excess of bromine was quenched by using saturated sodium sulphite solution and the product was extracted from DCM. The organic layer was combined, washed with water and dried over sodium sulphate. The product was then purified over silica gel, using column chromatography with hexane as eluent. The purified product was obtained at white solid $(0.08 \mathrm{~g}, 73 \%) .{ }^{1} \mathrm{H} \mathrm{NMR}\left(400 \mathrm{MHz}, \mathrm{CDCl}_{3}\right): \delta 8.55$ $(\mathrm{s}, 3 \mathrm{H}), 8.37(\mathrm{~s}, 3 \mathrm{H}), 7.70(\mathrm{~s}, 3 \mathrm{H}), 7.46(\mathrm{~s}, 3 \mathrm{H}), 2.98(\mathrm{~m}, 6 \mathrm{H}), 2.30(\mathrm{~m}, 6 \mathrm{H})$, $2.10(\mathrm{~m}, 12 \mathrm{H}), 0.99(\mathrm{~m}, 36 \mathrm{H}), 0.86(\mathrm{~m}, 48 \mathrm{H}), 0.75(\mathrm{~m}, 30 \mathrm{H}), 0.57(\mathrm{~m}, 18 \mathrm{H})$ ${ }^{13} \mathrm{C}$ NMR $\left(100 \mathrm{MHz}, \mathrm{CDCl}_{3}\right): \delta 156.06,151.98,149.02,145.67,140.34$, $138.90,138.21,133.95,124.95,120.21,118.58,117.00,116.69,55.61$, $55.39,41.32,37.40,36.02,31.67,29.60,29.35,28.80,26.75,23.92,22.68$, 22.16, 14.09. Anal. calcd for $\mathrm{C}_{120} \mathrm{H}_{168} \mathrm{Br}_{6}$ : $\mathrm{C}, 68.96 ; \mathrm{H}, 8.10$. Found: $\mathrm{C}$, $69.03 ; \mathrm{H}, 7.83$.

\section{Synthesis of compound 7}

To a solution of ExT $(0.20 \mathrm{~g}, 0.12 \mathrm{mmol})$ in carbon tetrachloride $\left(\mathrm{CCl}_{4}\right)(2.5$ $\mathrm{mL})$, copper bromide-alumina $(0.77 \mathrm{~g}, 1.73 \mathrm{mmoles})$ was added. The solution was stirred at $90^{\circ} \mathrm{C}$ for 24 hours. Upon completion of the reaction, the reaction mixture was filtered and washed with $\mathrm{CCl}_{4}$. The filtrate was collected and concentrated to obtain the crude product. The crude product was then purified over silica gel, using column chromatography with hexane as eluent. The purified product was obtained as white solid $(0.22$ g, 95\%). ${ }^{1} \mathrm{H}$ NMR $\left(400 \mathrm{MHz}, \mathrm{CDCl}_{3}\right): \delta 8.36(\mathrm{~s}, 3 \mathrm{H}), 7.72(\mathrm{~s}, 3 \mathrm{H}), 7.67$ (d, J $=8.6 \mathrm{~Hz}, 3 \mathrm{H}), 7.52-7.50(\mathrm{~m}, 6 \mathrm{H}), 3.03-2.96(\mathrm{~m}, 6 \mathrm{H}), 2.26-2.18(\mathrm{~m}, 6 \mathrm{H})$, 2.12-2.07 (m, 12H), 0.88-0.82 (m, 48H), 0.76-0.72 (m, 24H), 0.60-0.52 (m, $30 \mathrm{H}) .{ }^{13} \mathrm{C}$ NMR $\left(100 \mathrm{MHz}, \mathrm{CDCl}_{3}\right): \delta 153.29,151.67,148.97,144.67$, $141.66,139.87,139.73,139.47,138.95,126.89,123.02,119.69,114.26$ $113.25,55.49,55.00,41.34,37.72,34.02,32.12,30.28,29.56,29.36$, 29.15, 24.35, 22.83, 22.41, 14.31. Anal. calcd for $\mathrm{C}_{120} \mathrm{H}_{171} \mathrm{Br}_{3}: \mathrm{C}, 77.77 ; \mathrm{H}$, 9.30. Found: $\mathrm{C}, 77.42 ; \mathrm{H}, 9.24$

\section{Synthesis of ExT-P}

To a solution of $7(0.09 \mathrm{~g}, 0.05 \mathrm{mmol})$ in dry THF $(2.43 \mathrm{~mL}), 8(0.06 \mathrm{~g}, 0.17$ $\mathrm{mmol}$ ) was added with stirring under nitrogen atmosphere followed by $\mathrm{Pd}\left(\mathrm{PPh}_{3}\right)_{4}(0.005 \mathrm{~g}, 8 \mathrm{~mol} \%)$, TBAB and $2 \mathrm{M}$ aqueous solution of $\mathrm{K}_{2} \mathrm{CO}_{3}$ $(0.13 \mathrm{~g}, 0.97 \mathrm{mmol})$. The resultant reaction mixture was stirred at $90^{\circ} \mathrm{C}$ and the reaction was monitored by TLC. Upon completion, the reaction was quenched and the product was isolated in chloroform. The collected organic layer was washed with water. Then the solvent was evaporated and the crude product was purified through column chromatography over silica gel using hexane/ethyl acetate as the eluent. The product was isolated as a pale yellow solid $(0.07 \mathrm{~g}, 71 \%) .{ }^{1} \mathrm{H}$ NMR $(400 \mathrm{MHz}, \mathrm{CDCl} 3): \delta$ $8.51(\mathrm{~s}, 3 \mathrm{H}), 8.32-8.24(\mathrm{~m}, 6 \mathrm{H}), 8.23-8.18(\mathrm{~m}, 6 \mathrm{H}), 8.14-8.12(\mathrm{~m}, 9 \mathrm{H}), 8.04$ $(\mathrm{t}, \mathrm{J}=9.0 \mathrm{~Hz}, 9 \mathrm{H}), 7.91(\mathrm{~s}, 3 \mathrm{H}), 7.70-7.69(\mathrm{~m}, 6 \mathrm{H}), 3.16-3.14(\mathrm{~m}, 6 \mathrm{H}), 2.36$ $2.34(\mathrm{~m}, 6 \mathrm{H}), 2.24-2.23(\mathrm{~m}, 12 \mathrm{H}), 1.21-1.14(\mathrm{~m}, 36 \mathrm{H}), 0.97-0.88(\mathrm{~m}, 42 \mathrm{H})$, $0.80-0.78(\mathrm{~m}, 24 \mathrm{H}), 0.73-0.72(\mathrm{~m}, 12 \mathrm{H}), 0.64-0.61(\mathrm{~m}, 18 \mathrm{H}) .{ }^{13} \mathrm{C}$ NMR $(100$ $\mathrm{MHz}, \mathrm{CDCl} 3): \delta 153.99,145.64,139.70,139.44,138.39,131.76,131.25$, $130.76,128.86,128.74,128.53,127.90,127.68,127.58,126.21,125.66$, $125.35,125.29,125.23,124.97,124.90,56.13,37.21,31.77,29.86,29.74$, $24.30,22.56,14.20$. Anal. calcd for $\mathrm{C}_{168} \mathrm{H}_{198}$ : C, $91.00 ; \mathrm{H}, 9.00$. Found: $\mathrm{C}$, $90.52 ; \mathrm{H}, 9.23$.

\section{Acknowledgements}

The authors would like to acknowledge funding by Department of Science and Technology (DST) Government of India, grant number: TMD/CERI/BEE/2016/035/G. BK would like to acknowledge University Grants Commission, India for the research fellowship. Additionally, the authors would like to thank 
Prof. B. Jayaram, Department of Chemistry, Indian Institute of Technology Delhi for resources to perform the computation studies and Dr. Lutfan Sinatra of KAUST and Quantum Solutions LLC for PLQY measurements The research reported in this publication was supported by funding from King Abdullah University of Science and Technology (KAUST).

Keywords: Fluorescence $\cdot$ cross coupling $\bullet$ transient absorption spectroscopy $\cdot$ TDDFT $\bullet$ chromophore

a) S.-Y. Liu, W.-Q. Liu, J.-Q. Xu, C.-C. Fan, W.-F. Fu, J. Ling, J.-Y Wu, M.-M. Shi, A. K. Y. Jen, H.-Z. Chen, ACS Appl. Mater Interfaces 2014, 6, 6765-6775; b) D. S. Chung, J. W. Park, S.-O Kim, K. Heo, C. E. Park, M. Ree, Y.-H. Kim, S.-K. Kwon, Chem Mater. 2009, 21, 5499-5507; c) J. Kuwabara, T. Yasuda, S. J. Choi, W. Lu, K. Yamazaki, S. Kagaya, L. Han, T. Kanbara, Adv. Funct. Mater 2014, 24, 3226-3233.

[2] a) X. Wang, Z. Zhong, S. Zhao, T. Guo, J.-X. Jiang, J. Zou, L. Ying, J. Peng, Y. Cao, Org. Electron. 2018, 55, 157-164; b) X. Xu, X. Li, S. Wang, J. Ding, L. Wang, J. Mater. Chem. C 2018, 6, 9599-9606 c) H. Lee, H. Jung, S. Kang, J. H. Heo, S. H. Im, J. Park, J. Org. Chem. 2018, 83, 2640-2646.

[3] a) S. Katsuta, K. Tanaka, Y. Maruya, S. Mori, S. Masuo, T. Okujima, H. Uno, K.-i. Nakayama, H. Yamada, Chem. Commun. 2011, 47, 10112-10114; b) X. Zhan, J. Zhang, S. Tang, Y. Lin, M. Zhao, J. Yang, H.-L. Zhang, Q. Peng, G. Yu, Z Li, Chem. Commun. 2015 51, 7156-7159; c) F. Silvestri, A. Marrocchi, M. Seri, C. Kim, T. J. Marks, A. Facchetti, A. Taticchi, J. Am. Chem. Soc. 2010, 132 6108-6123; d) Y. Sakamoto, T. Suzuki, M. Kobayashi, Y. Gao, Y Fukai, Y. Inoue, F. Sato, S. Tokito, J. Am. Chem. Soc. 2004, 126 8138-8140; e) D. T. Chase, A. G. Fix, S. J. Kang, B. D. Rose, C. D. Weber, Y. Zhong, L. N. Zakharov, M. C. Lonergan, C. Nuckolls, M. M. Haley, J. Am. Chem. Soc. 2012, 134, 10349-10352.

[4] a) L. Edman, M. Pauchard, B. Liu, G. Bazan, D. Moses, A. J. Heeger, Appl. Phys. Lett. 2003, 82, 3961-3963; b) L. Edman, B. Liu, M. Vehse, J. Swensen, G. C. Bazan, A. J. Heeger, J. Appl. Phys. 2005 98, 044502; c) M. D. Weber, M. Adam, R. R. Tykwinski, R. D. Costa Adv. Funct. Mater. 2015, 25, 5066-5074.

[5] a) K. R. Justin Thomas, P. Singh, A. Baheti, Y.-C. Hsu, K.-C. Ho, J. T. s. Lin, Dyes Pigm. 2011, 91, 33-43; b) B. Nagarajan, S Kushwaha, R. Elumalai, S. Mandal, K. Ramanujam, D. Raghavachari, J. Mater. Chem. A 2017, 5, 10289-10300; c) S Higashijima, Y. Inoue, H. Miura, Y. Kubota, K. Funabiki, T. Yoshida, M. Matsui, RSC Adv. 2012, 2, 2721-2724; d) C. Teng, X. Yang, C. Yang, S. Li, M. Cheng, A. Hagfeldt, L. Sun, J. Phys. Chem. C 2010, 114, 9101-9110.

[6] a) J. Pei, J.-L. Wang, X.-Y. Cao, X.-H. Zhou, W.-B. Zhang, J. Am Chem. Soc. 2003, 125, 9944-9945; b) K. Shi, J. Y. Wang, J. Pei, Chem. Rec. 2015, 15, 52-72.

[7] J.-R. Cha, C.-W. Lee, M.-S. Gong, New J. Chem. 2015, 39, 3813 3820 .

[8] M. Pope, H. P. Kallmann, P. Magnante, .J. Chem. Phys 1963, 38, 2042-2043.

[9] X. Feng, W. Pisula, K. Müllen, Pure Appl. Chem. 2009, 81, 2203

[10] a) J. N. Moorthy, P. Natarajan, P. Venkatakrishnan, D.-F. Huang, T. J. Chow, Org. Lett. 2007, 9, 5215-5218; b) P. E. Gama, R. J. Corrêa S. J. Garden, J. Lumin. 2015, 161, 37-46; c) C. He, H. Guo, Q. Peng S. Dong, F. Li, Journal of Materials Chemistry C 2015, 3, 9942-9947; d) H. Liang, X. Wang, X. Zhang, Z. Liu, Z. Ge, X. Ouyang, S. Wang, New J. Chem. 2014, 38, 4696-4701.

[11] a) M. Zhu, C. Yang, Chem. Soc. Rev. 2013, 42, 4963-4976; b) Z.-L. Zhu, W.-C. Chen, L.-D. Zhang, X.-L. Liu, Q.-X. Tong, F.-L. Wong, F. Lu, C.-S. Lee, J. Mater. Chem. C 2016, 4, 6249-6255.

[12] a) D. Marsitzky, J. C. Scott, J. P. Chen, V. Y. Lee, R. D. Miller, S. Setayesh, K. Müllen, Adv. Mater. 2001, 13, 1096-1099; b) D. Thirion, C. Poriel, R. Métivier, J. Rault-Berthelot, F. Barrière, O. Jeannin, Chem. Eur. J. 2011, 17, 10272-10287.
Y. Jiang, Y.-X. Lu, Y.-X. Cui, Q.-F. Zhou, Y. Ma, J. Pei, Org. Lett. 2007, 9, 4539-4542

K. Lin, B. Xie, Z. Wang, R. Xie, Y. Huang, C. Duan, F. Huang, Y. Cao, Org. Electron. 2018, 52, 42-50.

a) X.-Y. Cao, X.-H. Zhou, H. Zi, J. Pei, Macromolecules 2004, 37, 8874-8882; b) Y. Wu, X. Hao, J. Wu, J. Jin, X. Ba, Macromolecules 2010, 43, 731-738; c) J. Huang, B. Xu, J.-H. Su, C. H. Chen, H. Tian, Tetrahedron 2010, 66, 7577-7582; d) C. Yao, Y. Yu, X. Yang, H. Zhang, Z. Huang, X. Xu, G. Zhou, L. Yue, Z. Wu, J. Mater. Chem. C 2015, 3, 5783-5794.

a) M. Liang, M. Lu, Q.-L. Wang, W.-Y. Chen, H.-Y. Han, Z. Sun, S. Xue, J. Power Sources 2011, 196, 1657-1664; b) X. Yang, Q. Zheng, C. Tang, D. Cai, S.-C. Chen, Y. Ma, Dyes Pigm. 2013, 99, 366-373; c) H.-W. Wen, P.-C. Yang, RSC Adv. 2016, 6, 60308-60317; d) X. Zong, M. Liang, T. Chen, J. Jia, L. Wang, Z. Sun, S. Xue, Chem. Commun. 2012, 48, 6645-6647.

Y. M. Sun, K. Xiao, Y. Q. Liu, J. L. Wang, J. Pei, G. Yu, D. B. Zhu, Adv. Funct. Mater. 2005, 15, 818-822.

X.-Y. Cao, X.-H. Liu, X.-H. Zhou, Y. Zhang, Y. Jiang, Y. Cao, Y.-X. Cui, J. Pei, J. Org. Chem. 2004, 69, 6050-6058.

B. Du, L. Wang, S.-C. Yuan, T. Lei, J. Pei, Y. Cao, Polymer 2013, 54, 2935-2944.

K. H. Lee, S. O. Kim, S. Kang, J. Y. Lee, K. S. Yook, J. Y. Lee, S. S. Yoon, Eur. J. Org. Chem. 2012, 2012, 2748-2755.

a) E. V. Dehmlow, T. Kelle, Synth. Commun. 1997, 27, 2021-2031;

b) A. L. Kanibolotsky, R. Berridge, P. J. Skabara, I. F. Perepichka, D. D. C. Bradley, M. Koeberg, J. Am. Chem. Soc. 2004, 126, 13695 13702.

S. Bayindir, M. Toprak, Spectrochim. Acta, Part A 2019, 213, 6-11. B. Kaur, D. Moghe, A. Dey, D. Kabra, J. Jacob, J. Lumin. 2018, 196, 511-519.

J. Luo, Y. Zhou, Z.-Q. Niu, Q.-F. Zhou, Y. Ma, J. Pei, J. Am. Chem. Soc. 2007, 129, 11314-11315.

W. Kwon, Y.-H. Kim, J.-H. Kim, T. Lee, S. Do, Y. Park, M. S. Jeong, T.-W. Lee, S.-W. Rhee, Sci. Rep. 2016, 6, 24205.

a) F. F. de Assis, J. M. de Souza, B. H. K. Assis, T. J. Brocksom, K. T. de Oliveira, Dyes Pigm. 2013, 98, 153-159; b) W.-J. Lin, W.-C. Chen, W.-C. Wu, Y.-H. Niu, A. K. Y. Jen, Macromolecules 2004, 37, 2335-2341.

S. Karuthedath, J. Gorenflot, Y. Firdaus, W.-Y. Sit, F. Eisner, A. Seitkhan, M. K. Ravva, T. D. Anthopoulos, F. Laquai, Adv. Energy Mater. 2019, 9, 1802476.

a) R. Tauler, Anal. Chim. Acta 2007, 595, 289-298; b) R. Tauler, A. Smilde, B. Kowalski, J. Chemom. 1995, 9, 31-58.

a) J.-L. Bredas, Mater. Horizons 2014, 1, 17-19; b) B. Kaur, D. Moghe, D. Kabra, J. Jacob, New J. Chem. 2019, 43, 2278-2288.

K. R. J. Thomas, P. Tyagi, J. Org. Chem. 2010, 75, 8100-8111.

T. M. McCormick, C. R. Bridges, E. I. Carrera, P. M. DiCarmine, G L. Gibson, J. Hollinger, L. M. Kozycz, D. S. Seferos, Macromolecules 2013, 46, 3879-3886.

W. R. Dawson, M. W. Windsor, J. Phys. Chem 1968, 72, 3251-3260. M. J. Frisch, G. W. Trucks, H. B. Schlegel, G. E. Scuseria, M. A Robb, J. R. Cheeseman, G. Scalmani, V. Barone, B. Mennucci, G. A. Petersson, H. Nakatsuji, M. Caricato, X. Li, H. P. Hratchian, A. F. Izmaylov, J. Bloino, G. Zheng, J. L. Sonnenberg, M. Hada, M. Ehara, K. Toyota, R Fukuda, J. Hasegawa, M Ishida, T Nakajima, Y. Honda, O. Kitao, H. Nakai, T. Vreven, J. A. Montgomery, Jr., J. E. Peralta, F. Ogliaro, M. Bearpark, J. J. Heyd, E. Brothers, K. N. Kudin, V. N. Staroverov, R. Kobayashi, J. Normand, K. Raghavachari, A. Rendell, J. C. Burant, S. S. lyengar, J. Tomasi, M. Cossi, N. Rega, J. M. Millam, M. Klene, J. E. Knox, J. B. Cross, V. Bakken, C. Adamo, J. Jaramillo, R. Gomperts, R. E. Stratmann, O. Yazyev, A. J. Austin, R. Cammi, C. Pomelli, J. W. Ochterski, R. L. Martin, K. Morokuma, V. G. Zakrzewski, G. A. Voth, P. Salvador, J. J. Dannenberg, S. Dapprich, A. D. Daniels, Ö Farkas, J. B. Foresman, J. V. Ortiz, J. Cioslowski, D. J. Fox, Gaussian 09 Rev. B.01, Wallingford, CT, 2009. a) X.-T. Zhang, L.-M. Fan, X. Zhao, D. Sun, D.-C. Li, J.-M. Dou, CrystEngComm 2012, 14, 2053-2061; b) C. He, Q. He, Q. Chen, L. Shi, H. Cao, J. Cheng, C. Deng, T. Lin, Tetrahedron Lett. 2010, 51, 1317-1321. 


\section{FULL PAPER}

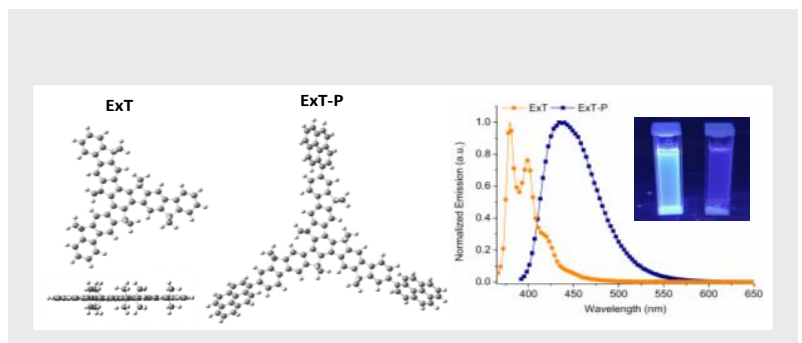

Banpreet Kaur, [a] Safakath

Karuthedath ${ }^{[b]}$ Catherine S. P. De

Castro, ${ }^{[b]}$ Frédéric Laquai, ${ }^{[b]}$ and

Josemon Jacob*la

Design, synthesis and selective functionalization of a rigid, truxene derived pure blue-emitting

chromophore

A novel, rigid, readily solution processable, blue emitting chromophore based on an extended core of truxene (ExT) and its trisubstituted pyrene derivative, ExT-P were designed and synthesized. The planar yet bulky nature of core prevents aggregation in solid state leading to pure blue emissions in ExT-P.

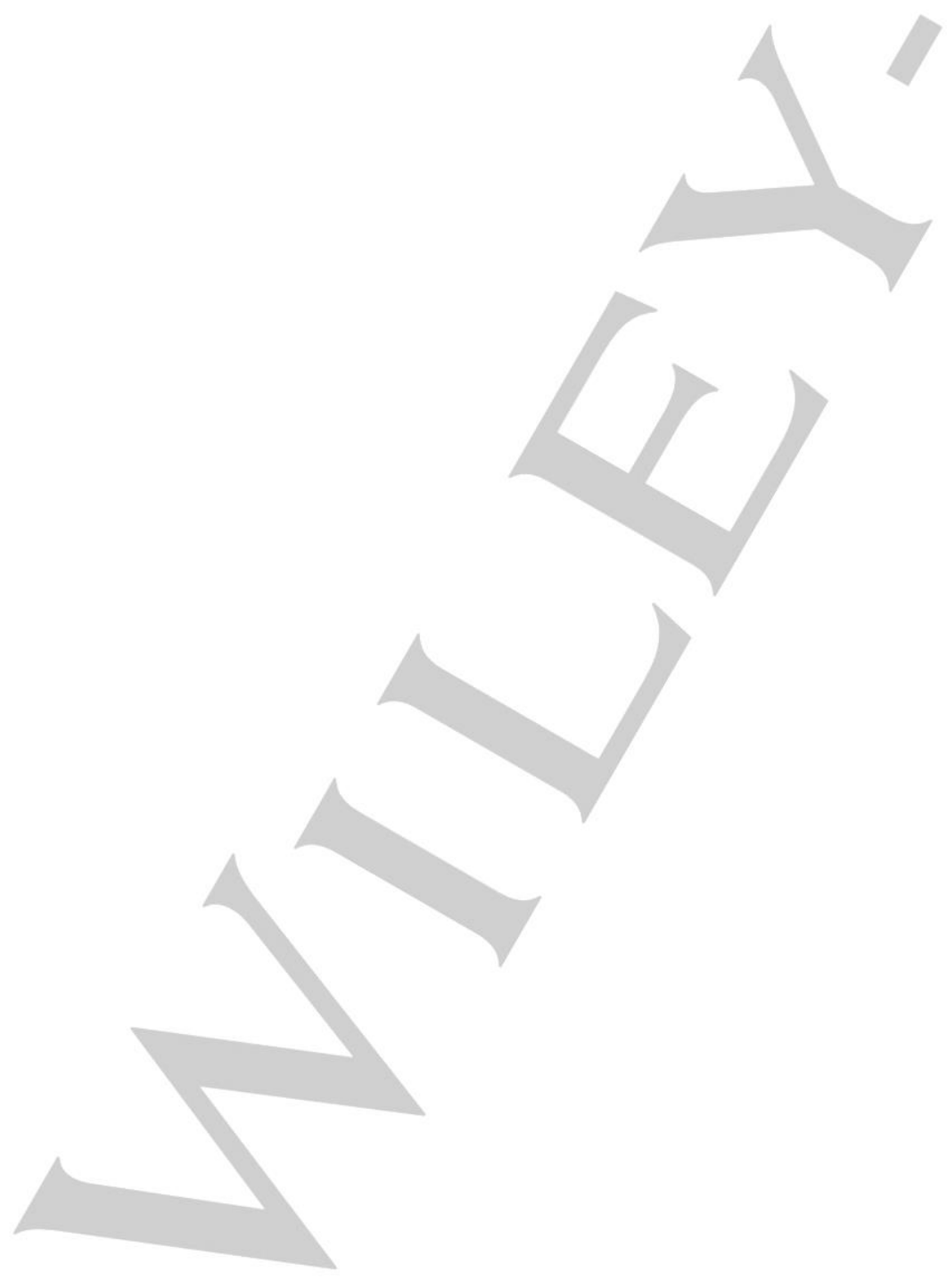

[a] B. Kaur, J. Jacob

Department of Materials Science and Engineering, Indian Technology Delhi, Hauz Khas, New Delhi 110016, India E-mail: jacob@mse.iitd.ac.in (J. Jacob)

[b] S. Karuthedath, C. S. P. De Castro, F. Laquai King Abdullah University of Science and Technology (KAU KAUST Solar Center (KSC), Physical Sciences and Engin Division (PSE), Material Science and Engineering Progran Thuwal 23955-6900, Kingdom of Saudi Arabia

Supporting information for this article is given via a link at the document. 